LETTER

\section{Abnormal retinal thickening is a common feature among patients with ARSACS-related phenotypes}

Autosomal-recessive spastic ataxia of Charlevoix-Saguenay (ARSACS) was first described among French Canadian patients from Québec presenting with a stereotypical triad of early-onset cerebellar ataxia, spastic paraplegia and peripheral neuropathy. Two recurring pathogenic mutations in the SACS gene were subsequently identified in these families in keeping with a mutational founder event in a geographically isolated population. ${ }^{1}$ However, ARSACS is being increasingly recognised worldwide as an important cause of inherited ataxia. ${ }^{2}$ Interestingly, non-Québec patients can show strikingly variable features marked by a lack of spasticity, cognitive impairment and a delayed age of onset. ${ }^{2}$ Given the heterogeneous clinical picture that can be associated with SACS mutations, the identification of ancillary features linked with these genetic defects could prove particularly useful in prioritising the most appropriate lines of investigations when confronted with a suspected case of ARSACS. Although prominent retinal hypermyelination is thought to be a characteristic manifestation of classical ARSACS among Québec patients, this ophthalmological finding has only been described infrequently in patients from Europe, Asia and the Middle East. ${ }^{2} \mathrm{~A}$ recent case report has even further argued that retinal 'hypermyelination' in ARSACS is a pathologically misleading term that should be abandoned in favour of retinal nerve fibre layer (RNFL) hypertrophy. ${ }^{3}$

To more accurately define the nature of the retinal findings in ARSACS and its possible practical relevance as a screening tool in routine clinical practice, we carried out a comprehensive neuro-ophthalmological examination of five patients from the North of England with molecularly confirmed ARSACS (table 1). ${ }^{4}$ Topographic analysis of the optic disc was performed with the Spectralis optical coherence tomography (OCT) platform (Heidelberg Engineering, Heidelberg, Germany).

No patient had evidence of retinal hypermyelination. Retinal striations were observed around the optic discs in four patients (A, B, C and D) and OCT measurements showed significant generalised peripapillary RNFL thickening (see online supplementary figures S1-S4). Patient E had no fundus abnormalities, and the peripapillary RNFL thickness was within the normal range for healthy controls (see online supplementary figure S5).

Our case series has provided convincing evidence that abnormal retinal thickening is a common, although not universal, feature among patients with ARSACS-related phenotypes secondary to pathogenic SACS mutations. Significant peripapillary RNFL thickening has also been previously reported in eight patients harbouring confirmed pathogenic SACS mutations with different OCT imaging platforms to the one used in our study. ${ }^{6-8}$ Classical myelinated retinal nerve fibres were not observed, and the current body of evidence, at least among non-Québec patients, suggests that retinal 'hypermyelination' has been used inappropriately to describe the striated appearance of a thickened RNFL around the optic discs. The pathophysiological basis for this observation remains to be determined, but it is rather revealing that the sacsin protein localises to mitochondria. In a transgenic knock-out mouse model, depletion of the sacsin protein resulted in disruption of mitochondrial axonal transport and cerebellar neurones with aberrant dendritic morphologies. ${ }^{9}$ Although speculative, RNFL thickening in ARSACS could therefore be related to axoplasmic stasis within the long axons of the retinal ganglion cells as they converge to form the optic nerve in the anatomically constrained region of the lamina cribosa.

The investigation of a large multicentre cohort of patients with ARSACS will be needed to determine whether the degree of RNFL thickening correlates with disease severity and progression or whether there are any specific genotype-OCT correlations. The molecular genetic basis of inherited ataxia and spastic paraplegia syndromes is highly heterogeneous-a situation that poses a number of diagnostic challenges in neurology clinics. In Friedreich's ataxia, which is the most common form of autosomal recessive ataxia, variable reduction in RNFL thickness has been reported among visually asymptomatic patients. ${ }^{10}$ In a recent OCT study, we found a normal RNFL profile among patients harbouring SPG4 mutations, which account for $\sim 40 \%$ of all autosomal-dominant cases of hereditary spastic paraplegia. ${ }^{11} \mathrm{~A}$ dilated fundus examination and OCT imaging should therefore be considered in patients with unexplained multisystem neurological disease. When present, retinal striations and RNFL thickening raise the distinct possibility of

Table 1 Clinical features and retinal nerve fibre layer measurements in patients with pathogenic SACS mutations

\begin{tabular}{|c|c|c|c|c|c|c|c|}
\hline \multirow[b]{2}{*}{ Patient } & \multirow{2}{*}{$\begin{array}{l}\text { Age } \\
\text { (years) }\end{array}$} & \multirow[b]{2}{*}{ Sex } & \multirow{2}{*}{$\begin{array}{l}\text { Onset } \\
\text { (years) }\end{array}$} & \multirow[b]{2}{*}{ Clinical features } & \multirow[b]{2}{*}{ SACS mutations } & \multicolumn{2}{|c|}{$\begin{array}{l}\text { Average RNFL } \\
\text { Thickness }\end{array}$} \\
\hline & & & & & & $\mathrm{OD}(\mu \mathrm{m})$ & OS $(\mu \mathrm{m})$ \\
\hline A & 48 & $\mathrm{~F}$ & 26 & $\begin{array}{l}\text { Gait ataxia, dysarthria, spastic paraplegia and } \\
\text { peripheral neuropathy }\end{array}$ & $\begin{array}{l}\text { c.2076delG (p.Thr692ThrfsX713); } \\
\text { c.3965_3966delAC (p.Gly1322ValfsX1343) }\end{array}$ & 174 & 175 \\
\hline B & 45 & M & 19 & $\begin{array}{l}\text { Gait ataxia, dysarthria, spastic paraplegia and } \\
\text { peripheral neuropathy }\end{array}$ & & 162 & 140 \\
\hline C & 43 & $M$ & Late-teens & $\begin{array}{l}\text { Gait ataxia, dysarthria, proximal myopathy and } \\
\text { peripheral neuropathy }\end{array}$ & $\begin{array}{l}\text { c.13048G >T (p.Glu4350X); } 0.7 \mathrm{Mb} \text { deletion } \\
(13 q 12.12)\end{array}$ & 138 & 122 \\
\hline D & 46 & M & Mid-teens & $\begin{array}{l}\text { Gait ataxia, dysarthria, proximal myopathy and } \\
\text { peripheral neuropathy }\end{array}$ & & 152 & 169 \\
\hline$E$ & 69 & M & Late-teens & $\begin{array}{l}\text { Gait ataxia, spastic paraplegia and peripheral } \\
\text { neuropathy }\end{array}$ & $\begin{array}{l}\text { c. } 1580 C>G(p . S e r 527 X) ; c .6781 C>A(p . \\
\text { Leu2261lle) }\end{array}$ & 111 & 86 \\
\hline
\end{tabular}


ARSACS, and SACS genetic screening should be considered.

\section{Patrick Yu-Wai-Man, ${ }^{1,2}$ Angela Pyle, ${ }^{1}$ Helen Griffin, ${ }^{1}$ Mauro Santibanez-Korev, ${ }^{1}$ Rita Horvath, ${ }^{1,3}$ Patrick F Chinnery ${ }^{1,3}$}

${ }^{1}$ Wellcome Trust Centre for Mitochondrial Research, Institute of Genetic Medicine, Newcastle University, Newcastle upon Tyne, Tyne and Wear, UK ${ }^{2}$ Department of Ophthalmology, Royal Victoria Infirmary, Newcastle upon Tyne, Tyne and Wear, UK ${ }^{3}$ Department of Neurology, Royal Victoria Infirmary, Newcastle upon Tyne, Tyne and Wear, UK

Correspondence to Dr Patrick Yu-Wai-Man, Wellcome Trust Centre for Mitochondrial Research, Institute of Genetic Medicine, Newcastle University, Newcastle upon Tyne NE1 3BZ, UK;

Patrick.Yu-Wai-Man@ncl.ac.uk

Correction notice The license of this article has also changed since publication to CC BY 4.0.

Contributors PY-W-M was responsible for drafting/ revising the manuscript for content, including medical writing for content, analysis or interpretation of data, acquisition of data; study supervision or coordination. $A P, H G, M S-K$ and RH were responsible for drafting/ revising the manuscript for content, including medical writing for content, analysis or interpretation of data. PFC was responsible for drafting/revising the manuscript for content, including medical writing for content, analysis or interpretation of data, and obtaining funding.

Competing interests PY-W-M is a Medical Research Council (MRC, UK) Clinician Scientist. PY-W-M also receives funding from Fight for Sight (UK) and the UK National Institute of Health Research (NIHR) as part of the Rare Diseases Translational Research Collaboration. $\mathrm{RH}$ is funded by the MRC (UK) and the European Research Council. PFC is a Wellcome Trust Senior Fellow in Clinical Science and a UK NIHR Senior Investigator. PFC also receives funding from the MRC
(UK), Parkinson's UK, and the UK NIHR Biomedical Research Centre for Ageing and Age-Related Disease award to the Newcastle upon Tyne Hospitals NHS Foundation Trust.

Ethics approval This study had the relevant institutional ethical approval and it complied with the Declaration of Helsinki.

Provenance and peer review Not commissioned; externally peer reviewed.

Data sharing statement There are no additional unpublished data relating to this study.

- Additional material is published online only. To view please visit the journal online (http://dx.doi.org/10. 1136/bjophthalmol-2013-304534)

Open Access This is an Open Access article distributed in accordance with the terms of the Creative

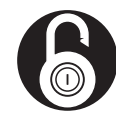

\section{OPEN ACCESS}

Commons Attribution (CC BY 4.0) license, which permits others to distribute, remix, adapt and build upon this work, for commercial use, provided the original work is properly cited. See: http:// creativecommons.org/licenses/by/4.0/

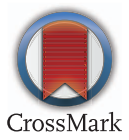

To cite Yu-Wai-Man $\mathrm{P}$, Pyle $\mathrm{A}$, Griffin $\mathrm{H}$, et al. Br J Ophthalmol 2014;98:711-712.

Accepted 23 December 2013

Br J Ophthalmol 2014;98:711-712.

doi:10.1136/bjophthalmol-2013-304534

\section{REFERENCES}

1 Engert JC, Berube P, Mercier J, et al. ARSACS, a spastic ataxia common in northeastern Quebec, is caused by mutations in a new gene encoding an 11.5-kb ORF. Nat Genet 2000:24:120-5.

2 Takiyama Y. Sacsinopathies: sacsin-related ataxia. Cerebellum 2007:6:353-9.

3 Garcia-Martin E, Pablo LE, Gazulla J, et al. Retinal nerve fibre layer thickness in ARSACS: myelination or hypertrophy? Br J Ophthalmol 2013;97:238-41.

4 Pyle A, Griffin H, Yu-Wai-Man P, et al. Prominent sensorimotor neuropathy due to SACS mutations revealed by whole-exome sequencing. Arch Neurol 2012:69:1351-4.

5 Pyle A, Griffin H, Duff J, et al. Late-onset sacsinopathy diagnosed by exome sequencing and comparative genomic hybridization. I Neurogenet 2013:27:176-82.

6 Pablo LE, Garcia-Martin E, Gazulla J, et al. Retinal nerve fiber hypertrophy in ataxia of Charlevoix-Saguenay patients. Mol Vis 2011;17:1871-6.

7 Desserre J, Devos D, Sautiere BG, et al. Thickening of peripapillar retinal fibers for the diagnosis of autosomal recessive spastic ataxia of Charlevoix-Saguenay. Cerebellum 2011;10:758-62.

8 Nethisinghe S, Clayton L, Vermeer S, et al. Retinal imaging in autosomal recessive spastic ataxia of Charlevoix-Saguenay. Neuro-Ophthalmology 2011:35:197-201.

9 Girard M, Lariviere R, Parfitt DA, et al. Mitochondrial dysfunction and Purkinje cell loss in autosomal recessive spastic ataxia of Charlevoix-Saguenay (ARSACS). Proc Natl Acad Sci USA 2012;109:1661-6.

10 Fortuna F, Barboni P, Liguori R, et al. Visual system involvement in patients with Friedreichs ataxia. Brain 2009:132:116-23.

11 Guthrie G, Pfeffer G, Bailie M, et al. The neurological and ophthalmological manifestations of SPG4-related hereditary spastic paraplegia. J Neurol 2012;260:906-9. 